\title{
Los antiguos y nuevos horizontes de la Dogmática penal
}

José L. González Cussac*

\section{Resumen}

La función de la doctrina penal no es hacer ciencia formulando pretensiones de verdad, sino que ha de conformarse y centrarse en resolver problemas prácticos, enjuiciando acciones humanas a través de las normas jurídicas vigentes de acuerdo con una serie de principios constitucionales. Su misión es diferente a la de pretender elaborar leyes universales científicas y someterlas a la experiencia y a su verificación o refutación. El valor central de la teoría jurídica del delito se contrae a la idea de justicia, que ha de hacerse efectiva mediante ciertas exigencias constitucionales de seguridad jurídica, eficacia, utilidad y libertad.

\section{Palabras clave}

Ciencia, doctrina penal, dogmática, metodología, neokantismo, neutralidad, seguridad jurídica, sistema, teoría del delito.

* Ph. D. Catedrático de Derecho penal de la Universidad de Valencia, España. 


\title{
Old and New Horizons of Criminal Dogma
}

\begin{abstract}
The role of criminal doctrine is not buiding up science by making truth claims, but it has to settle and focus on solving practical problems, examining human actions through the laws in force in accordance with a series of constitutional principles. Its mission is different from an attempt to draw scientific universal laws and to submit them to experience and to verification or refutation. The core value of the legal theory of crime is contracted to the idea of justice, which must be enforced by certain constitutional requirements of legal certainty, effectiveness, utility and freedom.
\end{abstract}

\section{Keywords}

Science, criminal doctrine, dogma, methodology, neokantism, neutrality, legal certainty, system, theory of crime. 


\section{Planteamiento}

Aceptemos como lugar común que la función y la justificación de la doctrina penal es ofrecer seguridad jurídica a través de un método racional de adoptar decisiones en derecho penal. La metodología generalmente empleada en el derecho continental europeo y latinoamericano es conocida como dogmática, consistente en una elaboración sistemática de la teoría jurídica del delito.

En la literatura penal en lengua española es ya un clásico la formulación de Gimbernat Ordeig (1990) acerca de esta cuestión:

La dogmática jurídico penal, pues, averigua el contenido del Derecho penal, cuáles son los presupuestos que han de darse para que entre en juego un tipo penal, qué es lo que distingue un tipo de otro, dónde acaba el comportamiento impune y dónde empieza el punible. Hace posible, por consiguiente, al señalar límites y definir conceptos, una aplicación segura y calculable del Derecho penal, hace posible sustraerse a la irracionalidad, a la arbitrariedad y a la improvisación. Cuanto menos desarrollada esté una dogmática, más imprevisible será la decisión de los tribunales, más dependerán del azar y de factores incontrolables la condena o la absolución (p. 15).

También es un lugar común admitir las limitaciones que la dogmática posee, independientemente de sus elaboraciones (Quintero, 2008, p. 623 y ss.). Así, pues, la dogmática tiene como misión identificar los problemas y luego ofrecer soluciones a los mismos, mediante teorías que posibiliten una aplicación del derecho positivo de un modo racional, previsible y seguro. La libre discusión en la comunidad jurídica permitirá que unas teorías se conviertan en dominantes y en todo caso abrirá el conocimiento para evaluar sus resultados, sus consecuencias, sus fundamentos, las objeciones, los errores y, por lo tanto, su revisión.

Sin embargo, como el citado autor advierte, expresando así una opinión generalizada, esta concepción contiene dos enunciados implícitos. Primero, que la dogmática penal presupone el derecho penal, es decir, que sin este no existe ni tiene sentido aquélla. Segundo, que la dogmática 'es una ciencia neutra', limitada a la interpretación correcta de la ley y, consiguientemente, independiente de las valoraciones y de las consecuencias a las que conduzca.

No creo que pueda discutirse la primera afirmación: la dogmática presupone el derecho penal. Pero no estoy tan seguro de la segunda, 
esto es, que la dogmática penal, y en general el derecho, pueda entenderse como una ciencia, y por consiguiente como valorativamente neutra. Precisamente en estas derivadas, y en su estrecha interrelación, estriba, a mi juicio, la discusión central sobre la función de la dogmática penal.

\section{El punto de partida: los sistemas 'neoclásicos' como ejemplos de 'ciencia neutra'}

El 'neokantismo' supuso la culminación de las sistemáticas clásicas, deahíque también selas conoce como'neoclásicas'. En ellas predominó una concepción decididamente analítica y, aunque introdujeran criterios axiológicos y un tímido giro de orientación teleológica, no lograron deshacerse plenamente de la rémora del positivismo, ni en su versión naturalista, ni en su tendencia normativista. Semejantes ataduras adquieren un protagonismo cuestionable en ámbitos tan cruciales como la teoría de las 'normas de cultura', o en la elaboración de la teoría jurídica del delito, esclava todavía de un ontologismo que se manifiesta sin disimulo al nuclearse sobre los conceptos de acción causal y resultado, o sobre un entendimiento en clave psicológica de la culpabilidad. Si a ello le unimos la visión marcadamente retribucionista de la pena, ya tenemos los parámetros necesarios para entender su fracaso (Gallas, 1959).

No es este el lugar para hacer balance del 'neokantismo', sino tan solo para recordar las razones por las que fue necesario abandonar su metodología, ante las insatisfactorias consecuencias a que conducía o debido a sus carencias o deficiencias al ofrecer soluciones a diversos grupos de problemas. Ello, desde luego, no significa restarle o desconocer sus innegables avances en el continuo desarrollo de la dogmática penal.

De modo que, con la única intención de desvelar sus fracasos, hemos de corroborar su incapacidad para superar el 'formalismo jurídico' del que el 'neokantismo' no deja de ser un fiel heredero. De hecho, hasta la tripartición clásica de la teoría del delito, propia de Liszt (1919), Beling (1936) o Rocco (1936, p. 236 y ss.) fue respetada sin parpadear por este grupo de autores. Así, Mezger (1935) y Sauer (1956) en Alemania, Delitala (1930), Maggiore (1949-1953) y Antolisei (1975) en Italia o Antón Oneca (1986) y Jiménez de Asúa (1931) en España, construyeron la teoría del delito sobre la acción, a la que añadieron las características de tipicidad, antijuridicidad y culpabilidad, además, claro, de la punibilidad. En este sentido, 
puede llamárseles revisionistas en cuanto corrigieron el formalismo jurídico, pero sin modificar los esquemas esenciales del mismo ${ }^{1}$.

Quizá uno de los mejores modos de comprobar el carácter revisionista del 'neokantismo' respecto al formalismo sea mediante el seguimiento del concepto de acción, auténtico eje central de ambas construcciones metodológicas. Este seguimiento alcanza su punto paradigmático en la obra de Radbruch, quien, según Schmidhäuser, describió claramente las dos estaciones posibles en este camino:

La superación de la búsqueda de un concepto superior (libre de valor) para la acción y la omisión y el rechazo definitivo de un concepto de acción como concepto superior, aun como sistema parcial, en favor de una sistemática teleológica (Schmidhäuser, 1975).

En efecto, en un primer momento, Radbruch se mantuvo fiel a la sistemática clásica, donde predominaba el método deductivo y clasificatorio ${ }^{2}$. Aceptó, en consecuencia, la existencia de un concepto superior al que podrían añadírsele luego diversas caracterizaciones especiales, para así poder construir el concepto de delito como último de la especie. Y este concepto superior fue la acción, como nexo entre voluntad, hecho y causalidad. Sin embargo, al no poder explicar con esta idea la omisión, él mismo se ve arrastrado por su afán clasificatorio, a reconocer la existencia de dos sistemas o especies de delito: los activos y los omisivos (Radbruch, 1930, pp. 151-167, especialmente pp. 161-163). Estas ideas corresponden a su etapa primera, dentro del formalismo, donde, en sintonía con Von Liszt o Beling, elabora la noción de delito desde un concepto superior, que es la acción, entendida de un modo netamente naturalístico.

Años más tarde, el mismo Radbruch expone su propia teoría de la acción de 1904 y la somete a una completa revisión. Reconoce el fracaso de una concepción naturalística de la acción, que en su intento clasificatorio le había conducido a dos clases de delito: los de acción y los de omisión, irreconducibles a un solo criterio. Igualmente, el formalismo inicial, basado en una construcción de compartimentos estancos donde a la tipicidad le correspondían todos los elementos descriptivo-objetivos, a la antijuricidad los elementos normativo-objetivos y a la culpabilidad los elementos subjetivo-descriptivos, había ido perdiendo las fronteras, hasta llegar a confundirse (Schmidhäuser, 1975, pp. 36-37). Ante este panorama, Radbruch rechazó el concepto naturalístico y prejurídico de acción como movimiento corporal voluntario con efectos 
en el mundo externo, pues así no resultaba posible expresar el tipo de un delito. En consecuencia, el concepto angular de la teoría del delito ya no podía ser la acción, sino la realización del tipo, donde quedaría expresada la significación lingüística y social del delito (Radbruch, 1930, pp. 151-167, especialmente pp. 161-163). Con ello, como señala Schmidhäuser (1975), el antiguo sistema, escindido en dos, acción y omisión, quedaba reunificado en uno solo, ahora centrado en la idea de realización típica. Se acentuaba así, ya desde el primer momento, el contenido material del hecho punible, y se comenzaban a tener presentes las consecuencias de la pena. Se entraba, pues, en un sistema valorativo y teleológico, es decir, en pleno auge del 'neokantismo' (pp. 37-38).

Por lo visto hasta ahora, parece más un análisis del modelo clásico o formalista que un examen del 'neokantismo'. Y en cierto modo es así, básicamente por dos razones. La primera resulta tan obvia como común a cualquier proceso evolutivo, pues las diversas construcciones dogmáticas no se suceden así como así de la noche a la mañana, sino que, muy por el contrario, responden a un continuo y lento devenir, cargado de influencias y herencias ${ }^{3}$. Y, en segundo lugar, que para nuestro objetivo es más importante, el 'neokantismo' nunca dejó de ser más que una corrección, muy transcendental si se quiere, del método clásico. En este sentido, fue tan enorme el lastre heredado del positivismo naturalista y normativista de finales del siglo XIX y principios del siglo XX, que, a pesar del giro axiológico impreso al mismo, sus partidarios nunca pudieron librarse de multitud de contradicciones ${ }^{4}$.

Esta corriente aportó a la ciencia del derecho en general y al derecho penal en particular notables avances, como el intento de delimitación frente al método de las ciencias naturales; la llamada al mundo de los valores; la importancia concedida a la categoría de bien jurídico; la apertura del sistema a las causas supralegales de justificación; la elaboración de la teoría normativa de la culpabilidad; el desarrollo de los elementos subjetivos del injusto; o la delimitación del objeto del derecho penal frente al objeto de la criminología. Sin embargo, pese a estos progresos, el sistema 'neokantiano' fracasó, lastrado por sus ataduras del pasado (Schünemann, 1991, pp. 47-53).

Este fracaso se debió, entre otras causas, a una insuperable contradicción, producto de una superposición metodológica. En efecto, sus defensores no pudieron armonizar la carga heredada del positivismo con sus nuevas aportaciones de naturaleza axiológica. 
Ello resulta claro en la dificultad de mantener, al mismo tiempo, un entendimiento positivista y valorativo de la norma. De ahí que M. E. Mayer (1937, p. 81 y ss.) creara las llamadas 'normas de cultura', donde residen los valores a los que la ley penal se refiere. Igualmente, para Mezger, la ley penal remite al "Derecho supralegal" (1965, p. 28).

Pero, del mismo modo, el dualismo metodológico se torna insostenible en el seno de la construcción de la teoría del delito. De una parte, su filosofía de los valores otorga un papel predominante al bien jurídico, y con él a la idea de realización del tipo como piedra angular del sistema. Sin embargo, para poder desarrollar una sistemática coherente con tal planteamiento, deberían haber previamente demolido las premisas del formalismo, y muy singularmente el concepto naturalístico de acción. Esta, heredada como concepto principal y superior de los filósofos hegelianos, seguía siendo entendida en su sentido causal (movimiento corporal más voluntariedad más nexo causal y resultado), esto es, como hecho externo-objetivo. De suerte que la acción continuó constituyendo la idea superior del sistema, puesto que era ella, y no el bien jurídico, la que servía como criterio delimitador y fundamentador del tipo. La acción siguió operando como eje del sistema, respecto a la cual se predicaban las características de tipicidad y antijuridicidad. Al mismo tiempo, como era definida en cuanto hecho objetivo-externo, y sobre ella se articulaban tipicidad y antijuridicidad, tenían difícil acomodo los elementos subjetivos del injusto (en parecidos términos, Kaufmann, 1975, p. 161).

En resumen, y para concluir esta esquemática aproximación crítica al modelo 'neokantiano', puede decirse que fracasó en cuanto no pudo armonizar una concepción causal de acción con una noción del tipo como tipo de injusto. Todo ello desembocó en las ya conocidas insuficiencias para ofrecer una explicación unitaria de los delitos de acción y de omisión, o de los delitos dolosos y culposos, o de los elementos subjetivos del tipo, etc. A estas deficiencias habría que añadir la no menos importante de su método en exceso formalista y abstracto, sumamente desconectado de la realidad y de las consecuencias prácticas a las que conducía. Es decir, la formulación de una 'ciencia neutra'.

En efecto, porque Mezger (1935, pp. 329-334, y 336-339), al igual que Beling, M. E. Mayer o Graf zu Dohna, admiten el 'complejo de las normas de cultura'. De suerte que como ninguna ley agota la totalidad del derecho, ha de afirmarse la existencia de un derecho 
supralegal. Las leyes -dirán- son emanación positiva del derecho, y esto es solo posible con arreglo a determinados presupuestos. Estos presupuestos de la ley constituyen el total 'complejo de cultura'. El derecho supralegal ha de tenerse en cuenta a la hora de la formación de conceptos jurídicos y en el momento de su interpretación.

Consecuentemente con esta concepción de la teoría de la norma, Mezger entiende que la idea de valor hace referencia a esas 'normas de cultura', más exactamente, que se trata de una manifestación concreta y determinada de estas. A partir de esta noción del derecho, en que la ley ya no es decisiva, sino que remite fuera de sí misma -al derecho supralegal y a los valores culturales que la integran, conformando el contenido del ordenamiento jurídico-se produce una idealización del concepto de bien jurídico, pues su contenido se aleja de la realidad, basándose directamente en ese etéreo derecho supralegal.

Este planteamiento ha sido acreedor de numerosas críticas. Baste aquí esgrimir alguna de ellas, como la que denuncia el relativismo axiológico al que conduce la sistemática neokantiana, al equiparar todas las posibles opciones valorativas. Además del riesgo político que ello comporta, supone una insalvable contradicción metodológica: parte de una tajante distinción entre los hechos que son y los valores que valen (deber ser), pero como quiera que los valores nacen de un 'complejo de cultura', esto es, de la realidad, acaban negando su punto de partida al derivar los valores de los hechos $(\text { realidad }=\text { complejo de cultura })^{5}$.

Pero ello conlleva todavía más problemas. Si las leyes contienen normas, y estas vienen a ser pretensiones intersubjetivas de validez, al situarlas fuera del ordenamiento jurídico, en un 'complejo de cultura' impuesto, no se sabe bien, ni por quién, ni cómo, ni cuándo, ni a qué racionalidad responden, ni tampoco si se ha seguido algún criterio de generalización en su creación (Habermas, 1996, pp. 380387). La teoría de la norma de Mezger -paradigma de toda una época-descansa, pues, sobre una base irracional e ideológicamente muy peligrosa ${ }^{6}$.

\section{Síntesis de la evolución posterior}

Retomemos nuestro punto de partida: la dogmática presupone el derecho penal y la dogmática penal es entendida como una ciencia, y consecuentemente como valorativamente neutra. Pues bien, conforme a este patrón de análisis, las concepciones dogmáticas 
mayoritarias elaboradas a partir del modelo clásico y neoclásico, mantienen sustancialmente este doble presupuesto.

Desde este punto de vista puede afirmarse que la 'teoría final de la acción' de Welzel mantuvo como premisa que el objeto 'como es' condiciona el método de la ciencia del derecho penal. De suerte que únicamente representó una variación en el entendimiento de la naturaleza del objeto, la acción, pero aceptando idénticas premisas centrales. Su 'nuevo sistema', precisamente, solo consistió en un entendimiento distinto de la acción. Para Welzel, la esencia de la acción humana es la finalidad: el ser humano anticipa medios, procedimientos y objetivos, y por consiguiente al actuar siempre persigue una finalidad -"supradeterminación final del querer" (Welzel, 1970, p. 56)-. De modo que la estructura óntica de la acción es la finalidad y esta estructura lógico-objetiva procede de la realidad, del mundo del ser, por lo que la teoría del delito, e incluso la ley y el legislador, deben asumirla. Este postulado constituye toda una declaración de principios: la dogmática jurídico-penal está determinada por una magnitud ontológica incuestionable y empíricamente demostrada. La derivada de este teorema es sencilla: el derecho penal es una ciencia y como tal está vinculado al objeto.

Ciertamente, esta compleja y elaborada concepción filosófica trató de superar el movimiento positivista, introduciendo nociones antropológicas y prejurídicas de la acción, convertida en la nueva base del sistema penal, pero revestida ahora de una pretensión de verdad absoluta, de auténtico enunciado científico. Desde una panorámica intra-sistemática, supuso cambios estructurales de enorme importancia; en efecto, porque si toda acción está dirigida hacia un fin, consciente y voluntariamente, el dolo pertenece a la misma acción y consecuentemente pasa a integrarse en la tipicidad. A partir de aquí la teoría del delito comienza a distinguir entre tipo objetivo, tipo subjetivo y culpabilidad.

Las principales críticas a este modelo se han dirigido precisamente contra sus inconsistentes y obsoletos presupuestos filosóficos, esto es, a la misma base de su concepción ontológica. Es decir, desde la perspectiva externa o de fundamentos de este sistema, en realidad, el finalismo carece de un modelo filosófico sólido y propio de referencia, sostenido por tanto en varias premisas acumuladas de los modelos filosóficos de origen, especialmente del neokantismo (Cobo del Rosal \& Vives Antón, 1990, pp. 288-289). Aunque no ocupa nuestra atención en este trabajo, el finalismo también ha recibido importantes 
críticas contra sus aspectos dogmáticos o sistemáticos (perspectiva interna $)^{7}$. A pesar de estas contundentes críticas y de su pérdida de protagonismo y seguidores, el modelo del finalismo ha ejercido una notoria influencia en las elaboraciones doctrinales posteriores. A destacar su notable contribución al desarrollo de una noción normativa de la culpabilidad, y a la impregnación del pensamiento penal de una orientación teleológica. Por todo ello, gráficamente se ha dicho que el finalismo es el puente entre el neokantismo y el presente (Mir Puig, 1982, p. 279), aunque no el único, ni siquiera en la doctrina alemana (Silva Sánchez, 1991, p. 12 y ss.).

Aunque en la actualidad persisten en la literatura penal exposiciones sistemáticas minoritarias fielmente seguidoras del modelo neoclásico o del finalista, lo cierto es que la doctrina alemana dominante se adscribe a un prototipo ecléctico o de síntesis de las dos anteriores. Esquemáticamente podría decirse que es heredera directa de las construcciones de Liszt, Beling y Radbruch. Así, la teoría del delito se mantiene con la aceptación del dibujo básico del finalismo, no tanto desde una perspectiva ontológica sino normativista, merced a la recuperación de las aportaciones de Engisch y Dohna, y al acogimiento del eclecticismo auspiciado por Gallas en un doble sentido: de una parte, combina el pensamiento sistemático con el tópico; y de otra, compagina las exigencias derivadas de una perspectiva ontológica con otras de naturaleza normativa, estas últimas mucho más acentuadas.

Ahorabien,lassistemáticasdominantesenlaactualidad, partiendo del eclecticismo señalado, se han visto impulsadas por el auge de las sistemáticas funcionalistas o racional-teleológicas (Schünemann, 1991, p. 31), generando una notoria influencia internacional. Al margen de sus ajustes en la esfera interna o sistemática del derecho penal, aquí nos interesa observar su contribución a los fundamentos del mismo ${ }^{8}$. Las diferentes corrientes funcionalistas comparten su distanciamiento del finalismo, bien por su oposición al método lógico-abstracto (Roxin) o por censurar su metodología ontológica (Jakobs). Al margen de sus notorias diferencias, coinciden en su carácter reactivo frente al formalismo jurídico con la pretensión de construir un derecho penal orientado a sus consecuencias (Silva Sánchez, 1991, p. 12).

Es interesante asomarse a los fundamentos últimos del derecho penal desde una óptica externa, especializada y autorizada en el pensamientojurídico, moral y político, es decir, desde la perspectiva de 
la filosofía. Pues bien, desde esta óptica es sabido que las sistemáticas eclécticas dominantes se sustentan en la corriente denominada funcionalismo, bien sea en su formulación más radical, estratégica o sistémica, o en otra más moderada, comúnmente denominada como funcionalismo teleológico (Vives Antón, 2011, p. 441 y ss.).

La corriente más influyente es esta última, la del funcionalismo teleológico, y se debe especialmente a la obra de Roxin. Un objetivo esencial para este autor es la preocupación por reconciliar la dogmática y la política-criminal, consciente del riesgo de orillar las consecuencias sobre la realidad surgidas del pensamiento sistemático. Para lograr esta reconciliación huyendo del distanciamiento entre ambas variables, propone una reconstrucción del derecho penal orientando la dogmática a las valoraciones político-criminales ${ }^{9}$. La clave de su discurso descansa en la categoría de los fines del derecho penal, singularmente en los fines de la pena, operando de distinta forma en cada uno de sus niveles estructurales. Con ello trata de configurar un sistema abierto, teleológico y práctico. Abierto, porque flexibiliza el sistema mediante la entrada en el mismo de criterios garantistas, es decir, mediante la introducción externa de criterios valorativos. Teleológico, por cuanto su sistema se perfila hacia las consecuencias del derecho penal. Y, práctico, en tanto busca compatibilizar el pensamiento sistemático y el pensamiento tópico (Roxin, 2004, p. 20).

El denominado funcionalismo estratégico o sistémico destaca -a los efectos que aquí nos interesan- por su absolutización del criterio funcional y el consiguiente rechazo de cualquier limitación procedente de la realidad o del lenguaje. La puridad metodológica se erige en su máxima preocupación y se lleva hasta sus últimas consecuencias. Así pues, al derecho penal se le atribuye una función sistémica, esto es, exclusivamente preventiva. De ahí que, más que ante una construcción normativa, nos encontramos ante una explicación sociológica en la que lo esencial es la estabilidad o funcionalidad social.

La trayectoria y génesis del funcionalismo es sobradamente conocida. Pero lo que hoy se entiende por funcionalismo no se corresponde exactamente con la concepción desarrollada por su creador, 'el príncipe del funcionalismo', Parsons, en la década de los treinta del pasado siglo ${ }^{10}$. Los cambios, las críticas, hasta la misma ambigüedad de su significado, han permitido afirmar que es el término más equívoco de los existentes en la sociología jurídica (Febrajo, 1975, p. 30). En realidad no existe una unidad funcionalista, 
pues dentro de esta corriente coexisten múltiples enfoques (Nagel, 1981, p. 468), pero esta disparidad no le ha restado influencia en el derecho, especialmente a través de la obra de Luhmann.

En esencia, el funcionalismo, en la formulación inicial de Parsons, toma la acción como categoría básica, entendida como todo proceso por el que los individuos forman sus intenciones y las hacen efectivas. La sociedad, y en su seno las personas, constituyen una unidad social concebida como un todo, como un sistema orgánico (organización cerrada a imagen de un organismo), que ha de tratarse de asegurar por todos los medios. A esta visión contribuye el concepto de 'rol' como unidad de conducta impersonal orientada hacia los otros actores. De aquí nace la noción de expectativas, ya que los demás esperamos y confiamos en que los otros desempeñen el papel que les corresponde. La necesidad de equilibrio, como algo connatural a todo sistema alcanza gran relevancia, pues cada función, cada proceso social, repercute en la estructura. La realidad social es la que distribuye e impone la asunción de 'papeles' sobre la base de un 'contrato-valor'. Por último, su visión de la 'conducta desviada', comprendida como falta o ausencia de pautas morales, es definida como una anomia (Bottomore, 1976, p. 27; Gouldner, 1979, p. 159 y ss., y 388-389; Gerth \& Wright 1984, p. 21 y ss.; Dahrendorf, 1974, p. 174.).

Entre las críticas recibidas por la propuesta examinada, subrayo las siguientes: su visión de la sociedad como una estructura estable y permanente, desemboca en una ideología conservadora incapaz de explicar el cambio y progreso social. También es incapaz de explicar la totalidad de los fenómenos sociales al reducirlo todo a la categoría de 'rol', que, a su vez, al ser concebido de forma tan rígida, anula toda posible capacidad de autonomía del individuo ('determinismo social'). E, igualmente, se ha censurado su idílica descripción de una sociedad en perfecto equilibrio, al entender que todo conflicto es evitable, al confiar ciegamente en la maleabilidad y en la conformidad del actor social con su 'papel'. Ello solo sería posible merced a un código moral común y a la esperanza en la resocialización del 'pecador' que incumpla o discrepe con la función asignada ('moral o religión de la resignación social') (Cfr. los autores citados en la nota anterior y también Bobbio, 1977, pp. 99-101; Boudon, 1981, p. 67 y ss.; Vives Antón, 2011, p. 175 y ss.).

Para evitar alguna de estas críticas, Luhmann (1983, pp. 16-27) imprime un giro a su propuesta. Ya no habla de 'estructuralismo 
funcionalista' sino de 'funcionalismo estructural'. De modo que lo esencial no será ya determinar el conjunto de condiciones necesarias para el mantenimiento de la estructura social, sino que la premisa descansa en la determinación de las condiciones necesarias para que se desarrolle la función exigida por las estructuras sociales. Persigue así evitar las críticas de inmovilismo, organicismo y conservadurismo, mediante la elaboración de una teoría del 'sistemaambiente', en la que se admiten cambios y mutaciones sociales. A partir de aquí, construye su sistema jurídico en el que sobresale una sujeción de la dogmática a presuponer las valoraciones impuestas por el legislador, con lo cual, las referencias axiológicas quedan fuera del sistema jurídico (Febrajo, 1975, pp. 29-30).

Pero este giro tampoco ha escapado a numerosas críticas. Se ha llegado a decir por Febrajo (1975) que, en realidad, no se diferencia en nada sustancial de la formulación inicial, salvo en un simple cambio terminológico. Para el citado autor el sistema jurídico propuesto es sumamente abstracto y puesto al servicio de la integración del individuo en la estructura social. Configura el derecho como un mecanismo de control y configuración social, cuya finalidad última sería mantener las 'desilusiones' sociales dentro de límites tolerables. Es decir, el derecho no desempeñaría una función de resolución de conflictos de intereses, sino que estaría destinado a asegurar el mantenimiento y la supervivencia del sistema. De aquí que quepa reproducir idénticas críticas, entre las que destaca el idealismo, la utopía y el voluntarismo (pp. 51-79).

El concepto funcionalista de derecho auspiciado por Luhmann ha recibido críticas demoledoras (Ferrari, 1987, p. 7 y ss.), pero entre ellas sobresale la expuesta por Habermas, quien comienza denunciando la renuncia a justificar las normas sobre el pretexto de irracionalidad, pues con ello niega toda posibilidad de una fundamentación basada en discursos (razón práctica). Al proceder así, equipara los hechos y las normas -los planos del 'ser' y del 'deber ser'- como funcionalmente equivalentes. Sin embargo, advierte un proceder 'sospechoso' en la conceptuación del derecho positivo, ya que Luhmann no lo concibe como el producto de una simple decisión ('decisionismo'), pues, entonces, un conjunto de normas así justificado, sin ninguna referencia legitimadora, dejaría de ser funcional. Por ello, se ve obligado a recurrir expresamente a la ideología como referente del mismo, y aunque esta descanse en el irracionalismo, no deja de operar con una apoyatura axiológica -llamada a los juicios de valor-, pero profundamente ideologizada, 
es decir, introduce los propios valores del intérprete (Habermas, 1988 , pp. 309, 320, 326, 382-387) $)^{11}$.

En el seno del derecho penal, las tesis funcionalistas, además de su explicación funcional de la sociedad y de las normas, reducen la acción humana a expectativas, al desempeño de roles y a primar la noción de deber, orientándose hacia finalidades preventivo generales. En su versión radical, supone un entendimiento meramente descriptivo y valorativamente neutro de la sociedad y del derecho. Ante una construcción tan vacía y subjetiva como peligrosa ideológicamente-pues puede explicar y justificar cualquier régimen político y jurídico-, los autores más moderados acuden a diversos correctivos de orientación teleológica y valorativa, esto es, se ven obligados a rescatar de un orden extrajurídico referencias axiológicas (Orts Berenguer y González Cussac, 2011, pp. 194-196). No obstante, hay que advertir que algunos penalistas adscritos a esta orientación, tampoco son exactamente fieles a los postulados fijados por el propio Luhmann (Vives Antón, 2011, p. 555 y ss.).

Me parece muy interesante llamar la atención acerca de la sintonía de este movimiento de raíz sociológica con el auge del 'derecho penal del riesgo'. La expansión del derecho penal trae causa en múltiples factores que han llevado a proclamar la "imposibilidad de volver al viejo y buen derecho penal liberal" (Silva Sánchez, 2001, p. 149) ${ }^{12}$. Pero sin duda, esta transformación aguda de modelo, una auténtica modificación estructural de hondo calado, también ha sido propiciada por el impulso que el funcionalismo ha conferido a la idea de peligro, erigiéndola en eje central del sistema. Por ejemplo, como advierte Silva Sánchez en referencia al emergente 'derecho penal de empresa', la estructura clásica sustentada en la prohibición directa del riesgo jurídicamente desaprobado, ha pasado a convivir con otros criterios más complejos: el riesgo permitido condicionado, el principio de precaución y la prohibición de la mera sospecha de riesgo (Silva Sánchez, 2013, p. 13). Como el propio autor citado incide, todo ello comporta un radical cambio de perspectiva, en el que la 'administrativización' del derecho penal, la noción de la 'gestión de riesgos' y la 'inocuización' cobran un protagonismo creciente en la doctrina mayoritaria actual.

De otra parte, desde un punto de vista teórico, el funcionalismo y su pretensión científica, ofrecen cobertura al renacimiento de un viejo fantasma superviviente en el seno del derecho penal liberal: la idea de peligrosidad. En efecto, porque su entendimiento de la 
acción como expectativa, sumado al fin del aseguramiento del sistema y la finalidad preventiva, propician el adelantamiento de la intervención penal desde cualquier posibilidad. Estrechamente vinculado con estas cuestiones debe hacerse referencia, aunque sea una simple evocación, al auge en nuestra disciplina de planteamientos procedentes de la neurociencia, un nuevo enfoque del derecho como ciencia y consecuentemente desde una pretensión de verdad (amplia y críticamente, Ramos Vázquez, 2013).

En resumen, puede decirse que los ejes de la discusión esencialmente han girado alrededor de dos ideas centrales: norma y acción. Una y otra condicionan la configuración del resto de categorías penales y, sobre todo, determinan la función y legitimidad atribuida al ius puniendi.

Sin restar importancia a aspectos metodológicos fundamentales, ni a los logros alcanzados en estas últimas décadas por el desarrollo de esta metodología sistemática (dogmática penal), el balance presenta ambigüedades en la utilización de algunos postulados, considerables variables ocultas y dosis altas de incertidumbre. En efecto, la labor teórica se ha concentrado en buena medida en polémicas estériles sobre categorías internas, con un alto grado de abstracción y nula repercusión práctica. Podría decirse que, mientras nuestro mundo cambia velozmente, sometiendo a todas las instituciones y relaciones personales, sociales, culturales, económicas y políticas a una transformación radical y profunda, numerosos teóricos penalistas continúan aferrados y ensimismados en bizantinas discusiones sobre la perfección del sistema de la teoría jurídica del delito. De suerte que el instrumento, el medio o la herramienta -la teoría jurídica del delito- han continuado absorbiendo el debate, mutando hasta convertirse en el fin supremo del mismo. Así, en lugar de tratar de comprender y ofrecer soluciones a estas modificaciones, la ciencia del derecho penal se enrocaba sobre sí misma.

Pero el excesivo protagonismo del estudio abstracto y dogmático de la teoría jurídica del delito, no solo ha desenfocado el análisis de sus categorías, sino que ha consolidado la tradicional desatención sobre el sistema de fuentes, los derechos y garantías fundamentales y sobre la teoría de las consecuencias jurídicas. El resultado ha sido un permanente distanciamiento con la jurisprudencia, con el poder legislativo y hasta con la opinión pública. Distanciamiento que no 
solo es de método, de perspectiva, sino también de lenguaje y en ocasiones parece que hasta de valores. Al incrementarse todas estas magnitudes hasta alcanzar un coeficiente de lejanía, como de dos galaxias que discurren en paralelo, el grado de influencia y utilidad práctica (aplicativa) de numerosas construcciones teóricas han descendido proporcionalmente.

La coexistencia de dos subsistemas superpuestos quizás sea una característica del modelo continental europeo y latinoamericano, muy diferente del desarrollado en los modelos anglo-americanos (críticamente con los pretendidos logros científicos de la dogmática penal alemana, Dubber, 2005, p. 1051 y ss.). En estos últimos no solo permanece una vocación más pragmática, expresada en el predominio del derecho procesal y en una mayor conexión con el derecho penal material (una aproximación comparativa entre los dos modelos, puede verse recientemente en Oxman, 2014), sino sobre todo en el énfasis del examen profundo de cuestiones constitucionales esenciales: en especial de la vigencia y grado de aplicación de los derechos fundamentales y de las garantías penales ${ }^{13}$.

Después de todo, no es ocioso recordar que -junto a la discusión sobre las categorías internas del sistema penal- los retos esenciales del derecho penal coinciden con las cuestiones que a su vez son centrales en la reflexión de la filosofía política y moral: la acción, la norma, el castigo, la responsabilidad, la libertad, etc. Desde esta premisa quizás sea posible evitar los escollos denunciados, especialmente los referidos al relativismo valorativo (neutralidad científica) y a la circularidad sistémica.

\section{El dilema del derecho penal: dogmática, política y ciencia}

\section{Derecho penal y política: Estado de Derecho y sistema de los derechos fundamentales.}

Históricamente ha existido siempre un enorme temor a reconocer cualquier tipo de conexión entre derecho y política. Este temor es patente en el seno de las corrientes positivistas y funcionalistas, en particular entre las más radicales. Pero quizá la cuestión se ha agudizado en los últimos tiempos como consecuencia de un cierto deterioro de la función del derecho en general, y del punitivo en especial, fruto de las profundas transformaciones sociales, económicas y culturales (Cuerda Arnau, 2010, p. 121 y ss.). 
Como explica Barcellona, el jurista actual se siente frustrado al haber perdido contacto con la realidad, pero se ve abocado a un dilema, porque si acepta la existencia de una compenetración entre derecho y política, parece sentirse a la vez constreñido a negar la autonomía y el carácter científico a su disciplina. Pero, si por el contrario niega la interrelación, subrayando la autonomía y cientificidad de la ciencia jurídica, debe permanecer con los ojos vendados frente a la realidad. De suerte que el precio por la comprensión puede ser la confusión y el miedo a lo desconocido, mientras que el precio de la autonomía científica puede ser la ceguera. A su juicio, la autonomía del derecho como ciencia se apoya en tres pilares básicos: la separación entre derecho y moral (Kant), la separación entre economía y política (Smith) y la separación entre Estado y sociedad civil (Savigny) (Barcellona; Hart y Mückenberger, 1977, pp. 32 y 45 ss.).

Por supuesto que la mayoría de la doctrina admite una clara influencia externa entre la política y el derecho. Históricamente ha quedado patente en la evolución de los diferentes modelos ideológicos de Estado. En este sentido, el derecho penal es fruto de cada una de las formas de organización del poder político. Así, nuestro actual derecho penal está indisolublemente vinculado al Estado social y democrático de Derecho.

Ahora bien, debemos preguntarnos si esta conexión entre política y derecho se limita a una mediatización meramente externa, o si por el contrario posee también una comunicación interna. Una primera respuesta a esta pregunta la encontramos dentro de las variadas corrientes del 'positivismo', del que en parte son tributarias las construcciones sistemáticas y funcionalistas del derecho penal. Sin embargo, esta afirmación precisa de importantes matizaciones.

Superado el inicial 'positivismo naturalista', dentro del 'positivismo jurídico' sobresale el denominado 'positivismo científico', cobijado en el más puro racionalismo. El derecho es comprendido como un sistema cerrado, sin lagunas, en el que solo cabe una interpretación jurídica, y libre de toda valoración política. En una etapa posterior podemos distinguir la aparición del 'positivismo legal' o 'normativista', sustentado en la convicción de que le ley agota en sí la idea de derecho y de justicia (Wieacker, 1957, p. 378 y ss.) ${ }^{14}$.

Con mayor precisión Bobbio ha distinguido hasta tres maneras distintas de entender el término 'positivismo'. El primer sentido 
designa un modo de acercarse al derecho caracterizado por una radical separación entre el derecho 'que es' y el derecho que 'debería ser'. En una segunda acepción, el positivismo del Estado, definido como conjunto de normas reguladoras del uso social de la fuerza, que proclama la supremacía de la ley y concibe las normas como imperativos. En tercer lugar, el positivismo se erige en una teoría de la justicia, que o bien la identifica con el derecho positivo, o bien sostiene como valor superior la obediencia a la ley con independencia de su significación moral (Bobbio, 1965, p. 378 y ss.). Cada una de estas tres formas de entender el positivismo son independientes entre sí (Hoerster, 1972, p. 11). A pesar de esta independencia, coinciden en sostener la distinción entre el derecho 'que es' y el derecho que 'deber ser'. De aquí que solo el primero pueda considerarse como objeto de la ciencia del derecho.

Frente a estas tesis positivistas, la misma pregunta ha sido contestada acertadamente por Habermas desde otro paradigma. Para él, afirmar la autonomía del sistema jurídico no puede significar una desconexión completa de derecho y política. El derecho, ni siquiera al convertirse en positivo, rompe sus relaciones internas con la política (p. 131).

Para Habermas (1991) el gran debate es el siguiente: por un lado, los fundamentos políticos -morales o éticos si se prefiere-del derecho positivo no pueden explicarse en forma de un derecho naturalracional superior ${ }^{15}$. Pero, por otra parte, no se le puede liquidar sin sustituirlo, so pena de privar al derecho de ese 'momento de incondicionalidad que precisa'. Entonces, hay que demostrar cómo puede situarse en el interior del derecho positivo el punto de vista de la política, representado por la formación imparcial del juicio de la voluntad colectiva. Sin embargo, para ello no basta con positivizar algunos de los principios del derecho natural-racional, ni siquiera es suficiente su instalación en el contenido de la Constitución ${ }^{16}$. Y no lo es porque todo en el derecho es contingencia y está sometido al cambio de la voluntad general. De ahí que la política, si se desea emplazarla en el derecho positivo, ha de poseer la trascendencia suficiente para garantizar un procedimiento que se regule a sí mismo, que controle su propia racionalidad (pp. 153-154).

La idea de un Estado de Derecho con división de poderes suministra la posibilidad de una legitimidad fundada en una racionalidad que garantice la imparcialidad de los procedimientos legislativos y judiciales. Este tipo de racionalidad procedimental, emigrada ya 
en parte al derecho positivo, constituye la única dimensión posible para asegurar al sistema jurídico y al derecho positivo un momento de incondicionalidad y una estructura sustraída al ataque constante de la contingencia. Ahora bien, cada una de las dos instancias, legislativa y judicial, reclama una diversa clase de racionalidad procedimental. En la primera es suficiente con preguntarse si los objetivos perseguidos para tomar una decisión son susceptibles de universalización, de asentimiento general (fundamentación de las normas). En cambio, a la hora de justificar las decisiones judiciales (aplicación de normas), la racionalidad procedimental necesaria para calificarla de imparcial no apela a qué hubiera hecho la mayoría, sino al criterio de haber tenido en cuenta de forma adecuada y completa todas las circunstancias relevantes según las reglas existentes en conflicto, y según los intereses afectados (Habermas, 1991, pp. 158-159).

En resumen, para Habermas solo entonces podrá hablarse de la racionalización de los procedimientos institucionalizados jurídicamente. Y esta idea nace del Estado de Derecho. Por lo tanto, afirmar la autonomía del sistema jurídico no significa predicar necesariamente una autonomía sistemática o cerrada sobre sí misma. La autonomía no es un atributo que el sistema jurídico posea por sí y para sí solo. Hablamos exclusivamente de autonomía en la medida en que los procedimientos institucionalizados para la producción legislativa y judicial garantizan una formación imparcial del juicio y de la voluntad común. Y por esta vía, afirma el mentado autor, penetra tanto en el derecho como en la política una racionalidad procedimental de tipo ético. Todas estas cuestiones remiten a la teoría del Estado, pues el mismo Habermas hace derivar todos sus argumentos de la idea del Estado de Derecho (1991, pp. 159-172).

Esta conexión entre teoría del Estado y derecho penal no ha pasado inadvertida en la doctrina penal. Varias son las aproximaciones propuestas, todas ellas trazando la conexión desde la ley fundamental de un Estado de Derecho, aunque sin embargo presentan importantes matices, que en mi opinión se pueden sintetizar en los tres siguientes. La primera fórmula, de carácter procedimental, establece una vinculación del derecho penal con la teoría del Estado, y por lo tanto con la Constitución, a través de los derechos fundamentales (en España, el autor más destacado en esta propuesta es Vives Antón (1977, p. 73 y ss.; 1982, p. 1 y ss.; 1992, pp. 248-255 y 2011, p. 663 y ss.). La segunda, sitúa el punto central de la conexión en la noción del Estado social (a destacar la iniciativa de Mir 
Puig, 1972). Y, la tercera vía, es sin lugar a dudas la más numerosa, $\mathrm{y}$, aunque también con planteamientos similares en la doctrina alemana ${ }^{17}$, su influencia en España se debe fundamentalmente a la obra de Bricola (1973), para quien la Constitución delimita al derecho penal de tal forma que incluso el orden penal de los bienes jurídicos ya viene perfectamente descrito y jerarquizado en la norma fundamental, por lo que ha podido incluso hablarse 'del programa penal de la Constitución' (en España, con algunos matices, siguen básicamente esta orientación, entre otros, los siguientes autores: González, 1984, p. 222 y ss., 1983; Arroyo Zapatero, 1987, p. 100 y ss.; y Álvarez García, 1991, p. 5 y ss.).

De las tres vías expuestas, me parece más sugerente la primera de ellas. Esto es, a través de una conexión con el Estado de Derecho, mediante el desarrollo de los derechos fundamentales, pues ellos constituyen el nervio del sistema democrático, y consecuentemente ofrecen un sólido presupuesto para construir y fundamentar el derecho penal en la actualidad (Carbonell, 1999). En este trabajo solo dispongo de espacio para exponer algunas razones muy básicas ${ }^{18}$.

Como dijera Radbruch (1971), la democracia es la única forma de gobierno apropiada para garantizar el Estado de Derecho. Democracia es simplemente un modo de ejercer el poder estatal, más exactamente, la forma de ejercerlo mediante el poder del pueblo. El valor de la democracia reside en la forma de tomar las decisiones (Maccormick, 1982, p. 27 y ss.).

En parecidos términos se pronuncia Alf Ross, para quien la idea fundamental de la democracia es la soberanía popular. En un sentido formal, significa que las decisiones son tomadas por el pueblo (soberanía). Por lo tanto, no indica el contenido, sino solo la forma de decidir en el ámbito político. La democracia es en realidad un método para decidir, y no apunta a un qué sino a un cómo se ejercita el poder. El núcleo conceptual está en la democracia política o jurídica, siendo esta "aquella forma de gobierno en que las funciones políticas son ejercidas por el pueblo con un máximo de intensidad (dimensión del grupo que puede participar), efectividad (control de los representantes) y latitud (extensión de la participación y control popular de todos los mecanismos de Gobierno) en los métodos parlamentarios" (Ross, 1989, pp. 24-25, 83-84 y 96-97). De modo que -continúa señalando Ross- la democracia no es un concepto de clase, sino que únicamente puede definirse respecto de un ideal. Y los ideales democráticos apuntan a su significado, a los valores relacio- 
nados con esa forma de gobierno. Entonces, no puede discutirse la tesis, pero sí la comprensión de los hechos en que esta se sustenta. Nos situamos así en el terreno de los efectos o consecuencias de la democracia. Ahora bien, la ciencia no puede efectuar la elección última, pero sí facilitarla. Quien renuncie a determinar científicamente los valores de un sistema, renuncia a discernir entre el bien y el mal y, por lo tanto, adopta una pasividad culpable. Los ideales democráticos se materializan en la libertad individual de actuar sin coacciones externas, en la libertad política (al ser la forma de gobierno que otorga mayor autonomía a sus ciudadanos), libertad de expresión, libertad de asociación, libertad de pensamiento, libertad personal (en cuanto ofrece mayor seguridad pública, ya que limita al máximo las intervenciones arbitrarias del propio Estado) e igualdad.

Desde este entendimiento de la democracia, se enlaza perfectamente con la vía propuesta por Vives Antón (1992), sobre la base de construir el derecho penal desde los derechos fundamentales, pues éstos "no son solamente garantías frente a los poderes públicos, ni concreción de una serie de valores sustantivos que la Constitución incorpora, sino que, tal vez de modo primario, representan las reglas básicas de procedimiento a las que ha de ajustarse la toma de decisiones en todo sistema democrático". Y este sería, precisamente, una forma de gobierno donde "los procedimientos de decisión solo pueden estimarse correctos si los ciudadanos han participado directamente o indirectamente en los mismos y si esa participación ha sido el fruto de una opción libre y racional" (Vives Antón, 1992).

Estos argumentos ofrecen sólida base para optar por las ideas de democracia y Estado de Derecho (derechos fundamentales) como motor legitimador y metodológico en la justificación y elaboración del derecho penal. Ello comporta fundamentales consecuencias en el sistema penal propuesto.

En primer lugar, la idea de libertad se sitúa como valor supremo del ordenamiento jurídico. En este sentido hemos visto cómo la esencia de la democracia la constituye el respeto hacia la personalidad moral del hombre, lo que Kant expresó en su imperativo categórico al señalar que el fin de la acción es tratar siempre a la humanidad como un fin y nunca como un medio. Manifestación especial de ello es el reconocimiento de su autonomía, de la libertad de autodeterminación conforme a los dictados de la propia personalidad (Ross, 1989, pp. 139140; Díaz, 1985, p. 28 y ss.). De modo que la libertad también se erige como eje de la teoría del derecho (Rawls, 1988). Y el derecho penal, 
como su ultima ratio, se configura como un orden destinado a asegurar la libertad, esto es, la coexistencia (Vives Antón, 2012, p. 169).

En segundo lugar, nos lleva a la concepción del derecho como un orden externo de convivencia, lo que comporta una separación clara entre derecho y moral (Hart, 1980, pp. 3-17). No debe confundirse el hecho de que el derecho apele para su legitimidad a una racionalidad procedimental de tipo ético, esto es, a una teoría de la justicia, con que persiga realizar mandatos morales a través de sus medios coactivos.

Tercero, la idea genérica de libertad, como capacidad de autodeterminación, no se agota aquí, sino que se extiende a otras manifestaciones. Aparece así, dicho muy esquemáticamente, el catálogo de derechos fundamentales, que constituyen el nervio del sistema democrático, y por ende de la Constitución. En este sentido sí podría hablarse de un concepto constitucional de delito, caracterizado por dos notas: el delito como infracción del derecho y el delito como lesión o puesta en peligro de bienes jurídicamente protegidos. El delito como infracción del derecho expresa un rasgo esencial del mismo: toda conducta delictiva aparece como violación de una norma concreta y, como ha señalado Vives Antón (1977), “cada norma concreta ha de ser entendida por referencia a una valoración fundamental, expresada en el concepto de derecho" (p. 88). De modo que la infracción del derecho, de la norma, es, en primera instancia, una conducta desvaliosa, en tanto que niega el valor recogido en el derecho positivo ${ }^{19}$. Y en segundo término, el delito como lesión o puesta en peligro de bienes jurídicos viene a significar que la idea de libertad "se concreta o materializa en una serie de bienes e intereses que representan las condiciones externas de su ejercicio" (Vives Antón, 1977, p. 90).

También desde la idea de libertad surge la construcción de un derecho penal de la culpabilidad (Fletcher, 2008, p. 57) y, aunque de ello no podemos ocuparnos con detenimiento en este trabajo, sí conviene aquí dejar constancia que la misma noción de Estado democrático conlleva la exigencia de libertad y con ella la proclamación de los contenidos propios del principio de culpabilidad $^{20}$.

Por último, todos los principios penales, como límites que son del ius puniendi, también derivan de la idea de Estado democrático de Derecho. En este sentido, Ross (1989) ha calificado la democracia 
como "un ingenioso sistema de asignación de poderes combinado con medidas de control" (p. 209). Así, la división de poderes, los mecanismos de control y, desde luego, la vigencia de los derechos fundamentales, sustentados en la dignidad de la persona -“el hombre como fin"- (Jiménez Redondo, 2013, p. 15 y ss.) suponen el nacimiento de límites infranqueables para el derecho penal de un Estado democrático de Derecho ${ }^{21}$.

\section{Dogmática, ciencia y razón práctica.}

De las alternativas surgidas recientemente frente a esta orientación dogmática funcionalista mayoritaria, tomaré como referencia la propuesta formulada por Vives Antón, entre otras razones, porque considero que trata de volver a conectar el estudio del derecho penal desde el pensamiento filosófico dominante.

Lo que Vives Antón califica como "insuficiencia de la dogmática penal" (2011), no presupone formular una nueva dogmática, sino justamente abandonar el camino de los dogmas o verdades científicas. De modo que, entonces, lo que conlleva su propuesta es sustituir esa dogmática entendida como algo verdadero, por una metodología que, partiendo de los derechos fundamentales, busque consensos estables y bien fundados, esto es, prácticas interpretativas consolidadas.

Siguiendo este razonamiento, podría decirse que la clase de preguntas formuladas por la dogmática penal -acción, dolo, imprudencia, causalidad, bien jurídico, imputabilidad, etc.-, se inscriben en una tendencia conectada con algunas confusiones filosóficas a las que Wittgenstein denominó 'ansias de generalidad'. El citado autor la caracterizó con la siguiente idea: un concepto general es una propiedad común de sus casos particulares, esto es, de que las propiedades son ingredientes de las cosas. Y en efecto, esta ansia de generalidad trae causa en el embrujo de toda teoría concebida como saber científico, que de una parte comporta reducir la explicación de los fenómenos naturales al menor número posible de leyes primitivas; y de otra, nos arrastra a una búsqueda desesperada de un objeto sobre el que hacer descansar nuestro pensamiento (modelo de objeto y designación) (Vives Antón, 2011, p. 463 y ss.).

De aceptarse este planteamiento, desde la perspectiva del derecho penal, la acción, la norma, el delito, ni ninguna de sus categorías o instancias (dolo, causalidad, bien jurídico, imprudencia) pueden ser entendidos como objetos del mundo, como pertenecientes al mundo 
del ser. Por lo tanto, su estudio, la dogmática, no es ninguna clase de ciencia. La función del derecho penal es enjuiciar si un determinado comportamiento humano es conforme o no a un conjunto de normas, y consiguientemente merecedor de ser castigado. A partir de ahí, el Derecho no puede ser configurado como un saber teórico (científico) sino como un saber práctico (hermenéutico). De modo que, el estudio del Derecho, como el de todos los conocimientos sociales, no es y no puede ser una ciencia en sentido estricto. Y no lo es, entre otras razones, porque no puede aplicar un método experimental para juzgar o decidir si una conducta infringe una norma y necesita ser sancionado el responsable (Orts Berenguer, González Cussac, 2011, p. 196 y ss.; Vives Antón, 2011, p. 503 y ss.).

En coherencia con estos presupuestos, tampoco es sostenible la existencia de un concepto universal y ontológico de acción. No existe un modelo matemático, ni una fórmula lógica, ni cualquier clase de teoría científica experimentada y verificada, que nos permita ofrecer un concepto de acción humana válido para todas las múltiples clases de acciones que el ser humano puede emprender y se encuentran reguladas en una norma. Es más, las acciones no existen antes de las normas (reglas) que las definen. En síntesis, la acción, cada acción, posee un significado determinado conforme a ciertas prácticas sociales (reglas o normas), que identifican un comportamiento humano frente a otros. Así puede decirse que la acción es el sentido o significado de un sustrato ${ }^{22}$.

En resumen, la función del derecho penal no es hacer ciencia formulando pretensiones de verdad, sino que ha de conformarse y centrarse en resolver problemas prácticos, enjuiciando acciones humanas a través de las normas jurídicas vigentes conforme a una serie de principios constitucionales. Su misión es diferente a la de pretender elaborar leyes universales científicas y someterlas a la experiencia y a su verificación o refutación. El valor central de la teoría jurídica del delito se contrae a la idea de justicia, que ha de hacerse efectiva mediante ciertas exigencias constitucionales de seguridad jurídica, eficacia, utilidad y libertad.

Los trabajos de Vives Antón muestran la insuficiencia de la dogmática para afrontar las tareas que corresponden a la doctrina, en orden a la mejor comprensión y aplicación del derecho positivo. Y en su lugar no propone una nueva dogmática, como algo mejor y verdadero, sino más bien abandonar la dogmática; que es tanto como decir, abandonar el camino metodológico sustentado en dogmas o 
verdades científicas, y sustituirlo por otro camino, que, partiendo de los derechos fundamentales, busque consensos estables y bien fundados (Orts Berenguer \& González Cussac, 2011, p. 196 y ss.; Vives Antón, 2011, p. 197).

En este sentido, la interpretación jurídica -la subsunción de un hecho en una norma-, comporta esencialmente fijar, de modo fiable, si ese comportamiento humano sigue una regla; e interpretar, establecer, si sigue una regla, es una práctica, no un presupuesto lógico. Entonces, la práctica interpretativa no se deduce de nuestros conceptos previos, sino de nuestros hábitos, de nuestras costumbres, de nuestra cultura y, en definitiva, de nuestra forma de vida. Razón por la cual en esta propuesta, tanto la jurisprudencia como la doctrina, poseen la misión de ofrecer usos estables y fiables, consensuados, de la interpretación. En consecuencia, no puede aceptarse la pretensión de imponer criterios hermenéuticos bajo la cobertura de una decisión científica irrefutable y verdadera. Cualquier metodología que pretenda arrogarse en exclusiva la verdad, se opone a los procedimientos democráticos basados en la libre discusión y la búsqueda de consensos mayoritarios. Prohibir y castigar pertenecen a la cultura cotidiana, se expresan en lenguaje común y son en última instancia competencia del pueblo.

Así, pues, concluyo con palabras de Vives Antón (2011) que el estudio del derecho penal

no puede ser ciencia; a saber, porque no trata de cómo hemos de concebir el mundo, sino de cómo hemos de actuar en él (...). Si algo ha quedado comprobado es que la autocomprensión cientifista, que tan a menudo acompaña el quehacer de la dogmática, no es sino un velo que oculta a los ojos del penalista el objetivo de su reflexión (...). El porvenir de la dogmática no reside es ninguna clase de perfeccionismo científico, sino en aquélla forma de perfeccionamiento que sirva para realizar más y mejor la función de la Carta Magna que von Liszt atribuyera al Derecho penal (pp. 495-496.).

\section{Notas}

1 Una amplia exposición del modelo 'neokantiano' puede verse en Mir Puig (1982, p. 227 y ss.). Desde una panorámica más amplia. Véase, Maurach 1949, p. 637 y ss.

2 Esquemáticamente, la teoría clásica del delito formuló una construcción bipartita, que ordenaba en dos categorías el estudio del delito: injusto 
y culpabilidad, de modo tal que todos los componentes objetivos de la acción se integran en el primero (acción, omisión, causalidad), y todos los requisitos subjetivos en la segunda (dolo, imprudencia, imputabilidad). Se levantaba desde un concepto causal de la acción: voluntad externa y producción de un resultado perceptible por los sentidos. Fue fruto de la influencia de las ciencias naturales y de su aspiración a alcanzar verificaciones empíricas que, en cierta forma, reducían el mundo en una doble clasificación: factores objetivos externos y procesos subjetivos internos (psíquico-psicológicos).

3 También Maurach $(1949$, p. 638) advirtió del equívoco de entender el derecho penal desde un punto de vista estático.

4 En efecto, la teoría neoclásica del delito no fue más que un ajuste o corrección de la anterior. Los cambios, en realidad solo aparentes, se debieron en gran medida a la necesidad de ofrecer una explicación mínimamente aceptable, en la aplicación de algunas figuras delictivas en las que resultaba insostenible mantener la tajante separación entre el binomio injusto-objetivo y culpabilidad-subjetivo. De modo que no hubo más remedio que admitir que el tipo podía quedar delimitado -en ciertas ocasiones- por la concurrencia de ciertos elementos subjetivos. No obstante esta concesión, el dolo y la imprudencia continuaban entendiéndose como formas de la culpabilidad. En consecuencia, la diferencia entre ambas categorías, tipo y culpabilidad, ya no podía dibujarse a partir de la separación entre lo objetivo y lo subjetivo, sino que tuvo que construirse sobre las ideas de dañosidad social y reprochabilidad. Por otra parte, se siguió manteniendo la concepción causal de la acción, aunque se intentó superar la influencia naturalista, apelando a la autonomía metodológica de las 'Ciencias del espíritu' y a la existencia de valores superiores desde los que se tenía que sustentar todo el Derecho.

5 En este sentido se pronuncia ampliamente Vives Antón (1979, pp. 360361).

6 Extensamente sobre estos peligros, el demoledor trabajo de Muñoz Conde (2003). De interés también, recientemente, Hoyer, A. (2009, p. 41 y ss.); y, Donini (2009, p. 13 y ss.).

7 En relación a las críticas dogmáticas, sobresalen, de una parte, las severas dificultades para explicar los delitos imprudentes, que, por definición, no son intencionales (esto es, no están predeterminados a una finalidad), $\mathrm{y}$, de otra, porque sus enunciados conducen a un inevitable fundamento subjetivo del injusto (Rodríguez Muñoz, 1978).

8 En síntesis sus principales cambios consisten esencialmente en el rechazo de la concepción ontológica de la 'acción final', con la asunción, en cambio, de sus consecuencias sistemáticas: el traslado del dolo al tipo 
subjetivo; el mantenimiento de criterios materiales como la dañosidad o la reprochabilidad; y la separación entre tipo (desvalor de acción y de resultado) y culpabilidad (actitud interna, poder actuar de otro modo, evitabilidad).

9 En esta línea, recientemente Muñoz Conde (2014, p. 117 y ss.).

10 El origen de la teoría de los sistemas sociales se remonta a la fisiología, en la obra de Malinowski, y al psicoanálisis de Freud (ampliamente, Nagel, 1981, p. 469 y ss.; y, Dahrendorf, 1974, p. 170).

11 Para este autor, las normas sí pueden ser racionales o irracionales, pues pueden justificarse en un discurso práctico, pero, en el plano ontológico, ni son verdaderas ni son falsas.

12 En todo caso, la expansión del derecho penal no es un fenómeno reciente, exclusivo de las sociedades post-industriales, sino que a lo largo de determinados periodos históricos de la edad moderna, significativamente durante las primeras décadas del siglo XIX, también se produjeron. (Sobre esta cuestión, Vormbaum, 2013, p. 213 y ss.).

13 El alejamiento de la política criminal elaborada por la doctrina tanto de la praxis como de la política real, así como el interesante reparto de papeles entre jurisprudencia y doctrina de una parte, y de otra el legislador, como juego de 'roles' en Italia, ha sido muy bien expuesta por Donini (2004, pp. 77 - 79).

14 Afirma que el primer vicio de la ciencia del derecho penal es el 'normativismo integral', esto es, la reducción del derecho a la mera norma, Donini, (2004, p. 67 y ss.).

15 Aquí Habermas se aparta y critica a Kant como gran artífice de la reconstrucción del Derecho natural-racional en el solar dejado por el Derecho natural-metafísico, porque supone una contradicción distinguir entre dos reinos autónomos: legalidad y moralidad, ya que si los dos pertenecen al juicio de la razón práctica, al desvincularlos completamente, uno pierde su competencia legisladora y el otro su positividad (Habermas, 1991, p. 131).

16 En esta línea resulta de gran interés la propuesta de Donini, quien argumenta la necesidad de anclar la ciencia del derecho penal no sólo en la norma, sino también en los principios. Con ello se exalta su vocación crítica y no meramente sistematizadora, ampliando el horizonte de su objeto a la política criminal "e incluso a la realidad que la política pretende gobernar" (2004, p. 83).

17 Debe significarse el trabajo de Rudolphi, (1970). Cfr. la exposición de Mir Puig (1976, p. 132 y ss.). 
18 Este planteamiento ya lo desarrollé en González Cussac (1994, p. 449 y ss.). También 1995, p. 10 y ss.). En sentido muy similar, destacando la idea de democracia, Donini (2004, p. 67 y ss.; expresamente en p. 85).

19 Indispensable distinguir en el seno de la pretensión general de justicia de las normas, entre su legitimación (dilucidar si la norma está racionalmente fundada), y otra en la que se examina si está correctamente aplicada al caso concreto (Martínez-Buján Pérez, 2013, p. 17).

20 Las normas jurídicas no pueden ser exclusivamente entendidas como mandatos, imperativos $\mathrm{u}$ órdenes, sino que también necesitan ser justificadas racionalmente para que sean válidas, dentro de un proceso de argumentación. Con otras palabras, las normas penales apelan a juicios de valor o a procesos racionales que las justifican, y en segundo lugar, fijan obligaciones de cumplimiento frente a todos los ciudadanosdestinatarios, que en el ejercicio de su libertad, pueden acatar o infringir.

21 Un reto creciente en el camino de legitimación constitucional del derecho penal surge del nuevo sistema de fuentes e instituciones supranacionales, en particular, en nuestro caso, de las europeas. Sobre este debate, Palazzo (2010, pp. 104 y ss), Bernardi (2011, pp. 15 y ss.) y Quintero Olivares (1999, pp. 51 y ss.).

22 Vives Antón (2011). Cuestiona el entendimiento de la acción en el Derecho penal como consecuencia de la concepción cartesiana, según la cual la acción era entendida como un hecho compuesto de un hecho físico (movimiento corporal) y de un hecho mental (la voluntad). Precisamente por la contribución de la mente era posible distinguir ontológicamente los hechos humanos de los hechos naturales y de los hechos de los animales. Pero el giro en la filosofía de la acción comporta un abandono de concepciones ontológicas y un cambio en la concepción de la acción. Se renuncia a un concepto ontológico de acción, como algo que sucede, como si fuera un fenómeno físico, y para evaluar si existe una acción ya no se acude a parámetros psicofísicos, mediante el recurso a la experiencia (nuestros sentidos son sólo hipótesis del mundo). La acción ha de entenderse de forma distinta, no como lo que las personas hacen, sino como el significado de lo que hacen, es decir, como el sentido de un sustrato. Todas las acciones no son meros acontecimientos, sino que tienen un sentido (significado), y por tanto no basta con describirlas, sino que es necesario entenderlas (interpretarlas). Frente a los hechos, que pueden explicarse conforme a leyes físicas, químicas, biológicas, o matemáticas, las acciones humanas han de ser interpretadas conforme a reglas o normas.

\section{Referencias}

Álvarez García, F. J. (1991). Bien jurídico y Constitución. Cuadernos de Política Criminal, 43, 5-44. 
Antón Oneca, J. (1986). Derecho Penal. Parte General (2ª . ed.). Madrid: Akal.

Antolisei, F. (1975). Manuale de Diritto Pellale. Parte Generale. (7ª ed.). Milano: Giuffrè.

Arroyo Zapatero, L. (1987). Fundamento y función del sistema penal: El programa penal de la Constitución. Revista Jurídica de Castilla-La Mancha $1,97-110$.

Barcellona, P., Hart, D. y Mückenberger, U. (1977). La formación del jurista (trad. C. Lasarte). Madrid: Civitas.

Beling, E. (1936). El rector de los tipos de delito (trad. L. Príeto Castro y J. Aguirre) ( $1^{\mathrm{a}}$ ed.). Madrid: Reus.

Bernardi, A. (2011). Aproximación a la construcción constitucional del Derecho penal en relación a las fuentes e instituciones europeas (trad. M. Macías; M. Mazzon; y, R. M. Carlés). Revista Penal 27, 15-40.

Bobbio, N. (1965). El problema del positivismo jurídico. Buenos Aires: Editorial Universitaria.

Bobbio, N. (1977). Dalla struttura alla funzione. Nuovi studi di teoría del Diritto ( $2^{\mathrm{a}}$ ed.). Milano: Edizioni di Comunità.

Bottomore, T. B. (1976). La sociología como crítica social (trad. A. Monrabá). Barcelona: Península.

Boudon, R. (1981). La lógica de lo social (trad. L. Horno Lliria). Barcelona: Rialp.

Bricola, F. (1973). Teoría general del reato. Novissimo Digesto italiano (pp. 7-93), Vol. XIV, Torino: Utet.

Carbonell, J. C. (1999). Derecho penal. Concepto y principios constitucionales (3a ed.). Valencia: Tirant lo Blanch.

Cobo Del Rosal, M. \& Vives Antón, T. S. (1990). Derecho Penal. Parte General ( $3^{a}$ ed.). Valencia: Tirant lo Blanch.

Cuerda Arnau, M. L. (2010). Dogmática, derechos fundamentales y justicia penal: análisis de un conflicto. Teoría E Derecho. Revista de Pensamiento Jurídico, 8, 121-140.

Dahrendorf, R. (1974). Sociedad y Sociología (trad. J. Benlloch). Madrid: Tecnos.

Delitala, G. (1930). Il "fatto" nella teoria generale del 'reato'. Padova: Cedam.

Díaz, E. (1985). La justificación de la democracia. Revista Sistema. Revista de Ciencias Sociales 66, 3-23. 
Donini, M. (2004). La relación entre derecho penal y política: método democrático y método científico (trad. C. Méndez Rodríguez). Revista Penal 13, 67-84.

Donini, M. (2009). La gestión del paso del Fascismo a la Democracia en Italia: Apuntes sobre la memoria histórica y la elaboración del pasado 'mediante' el derecho penal, (trad. J. A. Ramos Vázquez). Revista Penal, $23,13-32$.

Dubber, M. D. (2005). The promise of German Criminal Law: A Science of Crime and Punishment. German Law Journal, 6(7),1049-1071.

Fletcher, G. (2008). Gramática del derecho penal (trad. F. Muñoz Conde). Buenos Aires: Hammurabi.

Febrajo, A. (1975). Funzionalismo strutturale e sociología del Diritto nell'Opera di Niklas Luhmann. Milano: Giuffrè.

Ferrari, V. (1987). Funzioni del Diritto. Roma-Bari: Laterza.

Gallas, W. (1959). La teoría del delito en su momento actual (Trad. Córdoba Roda). Barcelona: Bosch.

Gerth, H. \& Wright Mills, C. (1984). Carácter y estructura social. La psicología de las instituciones sociales (trad. E. Gelín y J. Balan)., Barcelona: Paidós.

Gimbernat Ordeig, E. (1990). ¿Tiene un futuro la dogmática jurídico-penal? En E. Gimbernat Ordeig, Estudios de Derecho Penal (3 ${ }^{\mathrm{a}}$ ed., pp. 140-161). Madrid: Tecnos.

González Cussac, J. L. (1995). Derecho penal y Teoría de la democracia. En L. Martínez Vázquez de Castro. Historia y Derecho (Estudios jurídicos en Homenaje al Profesor Arcadi García Sanz) (pp. 449-460). Valencia: Tirant lo Blanch.

González Rus, J. J. (1983). Bien jurídico y Constitución (Bases para una teoría). Madrid: Fundación Juan March.

González Rus, J. J. (1984). Teoría de la pena y Constitución. En Estudios Penales y Criminológicos VII (pp. 224-280), Santiago: Universidad de Compostela.

Gouldner, A. W. (1979). La crisis de la sociología occidental (trad. N. A. Miguez). Buenos Aires: Amorrortu Editores.

Habermas. J. (1996). La lógica de las ciencias sociales (trad. M. Jiménez Redondo). Madrid: Tecnos.

Habermas, J. (1991). Escritos sobre moralidad y eticidad (trad. M. Giménez Redondo). Barcelona: Paidós. 
Hart, J. L. A. (1980). El nuevo desafío al positivismo jurídico (trad. L. del Hierro, F. Laporta y J. R. Páramo). Revista Sistema 36, 3-17.

Hoyer, A. (2009). Ciencia del Derecho Penal y nacionalsocialismo (trad. F. Guanarteme). Revista Penal, 23, 41-51.

Hoerster, N. (1972). En defensa del positivismo jurídico (trad. J. M. Seña) (1 ed). Barcelona: Gedisa.

Jiménez Redondo, M. (2013). El hombre como fin en sí: una aproximación kantiana a la idea de persona. Teoría E Derecho Revista de pensamiento jurídico 14, 14-33.

Kaufmann. A. (1975). Sobre el estado de la doctrina del injusto personal (trad. L.H. Schiffrin). Revista Nuevo Pensamiento Penal 5-8, 159-181.

Liszt, F. von (1919). Lehrbuch des deutschen Strafrechts (22 ${ }^{\mathrm{a}}$ ed.). BerlínLeipzig: Walter de Gruyter.

Liszt, F. von (1914-1929). Tratado de Derecho Penal (trad. Q. Saldaña), tomos II y III (trad. L. Jiménez de Asúa y notas de Q. Saldaña) ( $3^{\text {a }}$ ed.). Madrid: Reus.

Luhmann, N. (1983). Sistema jurídico y dogmática jurídica (trad. I. De Otto Pardo). Madrid: Centro de Estudios Constitucionales.

Maggiore, G. (1949-1953). Diritto Penale. Parte Generale. Tomos I y II. Bologna: Zanichelli.

Martínez-Buján Pérez, C. (2013). El contenido de la antijuricidad. Valencia: Tirant lo Blanch.

Maccormick, N. (1982). Legal right and social democracy. Oxford: Oxford University Press.

Maurach, R. (1949). L' evoluzione della dogmatica del reato nel più recente Diritto Penale germanico. Rivista Italiana di Diritto Penale, 2 (6) 637-657.

Mayer, M. E. (1937). Filosofía del Derecho. Barcelona: Labor.

Mayer, M. E. (1965). Rechtsnormen und Kulturnormen. Darmstadt: Wissenschaftliche Buchgesellschaft.

Mezger, E. (1935). Tratado de Derecho Penal. Tomos I y II (trad. J. A. Rodríguez Muñoz). Madrid: Revista de Derecho privado.

Mir Puig, S. (1972). Función de la pena y teoría del delito en el Estado social y democrático de Derecho (2a . ed.). Barcelona: Bosch.

Mir Puig. S. (1982). Introducción a las bases del Derecho Penal. Barcelona: Bosch. 
Muñoz Conde, F. (2003). Edmundo Mezger y el Derecho Penal de su tiempo (4 ed.). Valencia: Tirant lo Blanch.

Muñoz Conde, F. (2014). Dogmática jurídico-penal y Política-criminal: una relación conflictiva, pero necesaria. En: Revista Penal 33, 117-129.

Nagel, E. (1981). La estructura de la ciencia (trad. N. Míguez). Barcelona: Paidós.

Orts Berenguer, E. y González Coussac, J. L. (2011). Compendio de Derecho Penal. Parte General ( $3^{\mathrm{a}}$ ed). Valencia: Tirant lo Blanch.

Oxman, N. (2014). Sistemas de imputación subjetiva. Valencia: Tirant lo Blanch.

Palazzo, F (2010). La legalidad y la determinación de la ley penal: El significado lingüístico, la interpretación y el concepto de la regla iuris (trad. I. Melero y S. Barón). Revista Penal 25, 104-116.

Quintero Olivares, G. (2008). Algunas limitaciones de la dogmática. En: C. García Valdés et al (Coord.). Estudios Penales en Homenaje a E. Gimbernat Ordeig (pp. 623-638) vol. I. Madrid: Edisofer.

Radbruch. G. (1930). Zur Systematik der Verbrechenslehre, En A. Hegler (Ed.), Beiträge zur Strafrechtswissenschaft. Festgabe für Reinhard von Frank zum 70. Geburtstag (pp. 158-173), tomo I. Tübingen: J. C. B. Mohr.

Radbruch, G. (1967). Der Handlungsbegriff in seiner Bedeutung für das Strafrechtssystem. En A. Kaufmann (Ed.), Der Handlungsbegriff in seiner Bedeutung für das Strafrechtssystem: zugleich ein Beitrag zur Lehre von der rechtswissenschaftlichen Systematik (pp. 1-150). Darmstadt: Wissenschaftliche Buchgesellschaft.

Radbruch, G. (1971). Derecho por encima de las leyes y leyes que no son Derecho. En G. Radbruch, E. Schmidt, H. Welzel. Derecho injusto v derecho nulo (trad., J. M. Rodríguez Paniagua). Madrid: Aguilar.

Ramos Vásquez, J. A. (2013). Ciencia, libertad y Derecho penal. Valencia: Tirant lo Blanch.

Rawls. J. (1988). Las libertades fundamentales y su prioridad. En S. M. McMurrein (Ed.). Libertad, igualdad y derecho (trad. G. Valverde Gefaell, pp. 9-90). Barcelona: Ariel.

Rocco. A. (1933). Il problema e il metodo della scienza del Diritto penale. En: A. Rocco. Opere Giuridiche (vol. III, pp. 263 ss.). Roma: Società editrice del Foro Italiano.

Rodríguez J. A. (1978). La doctrina de la acción finalista (2a ed.). Universidad de Valencia: Secretariado de Publicaciones. 
Ross, A. (1989). ¿Por qué democracia? (trad. R. J. Vernengo). Madrid: Centro de Estudios Constitucionales.

Roxin, C. (2004). ¿Qué puede reprimir penalmente el Estado? Acerca de la legitimación de las conminaciones penales. En C. Roxin Problemas actuales de la Dogmática penal (trad. M. Abanto, p. 20 y ss.). Lima: Ara Editores.

Rudolphi, H. J. (1970). Die verrchiedenen Aspekte des Rechtsgutbegriff. Festschrift für R.M. Hönig zum 80. Geburtstag (pp. 151-167). Gottingen: O. Schwartz.

Sauer, G. (1956). Derecho Penal. Parte General (trad. J Cerezo y J. del Rosal). Barcelona: Bosch.

Schmidhäuser, E. (1975). Sobre la sistemática de la teoría del delito: Un tema fundamental de Radbruch desde el punto de vista de la nueva dogmática (trad. J. Bustos Ramírez). Nuevo Pensamiento Penal. IV (5), 33-46.

Schünemann, B. (1991). El sistema moderno de derecho penal: cuestiones fundamentales (trad. J. Mª Silva Sánchez). Madrid: Tecnos.

Schünemann, B. (1991). Introducción al pensamiento sistemático en Derecho penal. En: El sistema moderno del Derecho penal: cuestiones fundamentales (trad. J-M Silva Sánchez, pp. 31-80). Madrid: Tecnos.

Silva Sánchez, J. M (1991). Prólogo. En B. Schünemann, Sistema moderno del Derecho penal (pp. 11-22). Madrid: Tecnos.

Silva Sánchez, J. M. (1992). Aproximación al Derecho penal contemporáneo. Barcelona: J. M. Bosch.

Silva Sánchez, J. M (2001). La expansión del Derecho penal (2 ${ }^{\mathrm{a}}$ ed.). Madrid: Civitas.

Silva Sánchez, J. M (2013). Criminalidad de empresa y Compliance. Barcelona: Atelier.

Vives Antón, T. S. (1977). Reforma política y Derecho penal. Cuadernos de Política Criminal, 1, 73 y ss.

Vives Antón, T. S. (1979). Dos problemas del positivismo jurídico. En Escritos Penales (pp. 343-368). Valencia: Colección de Estudios del Instituto de Criminología y Departamento de Derecho penal de la Universidad de Valencia.

Vives Antón, T. S. (1982). Introducción: Estado de Derecho y Derecho penal, en M. Cobo del Rosal, (dir.) y M. Bajo Fernández, (Coord.), Comentarios 
a la legislación penal (pp. 1-48), Tomo I, Derecho penal y Constitución. Madrid: Edersa.

Vives Antón, T. S. (1992). La reforma del proceso penal. Valencia: Tirant lo Blanch.

Vives Antón, T. S. (2011). Fundamentos del sistema penal (2 ${ }^{\mathrm{a}}$ ed.). Valencia: Tirant lo Blanch.

Vives Antón, T. S. (2012). La Ley, lenguaje y libertad: (sobre determinismo, libertades constitucionales y Derecho penal). Teoría \& Derecho. Revista de Pensamiento Jurídico, 11, 168-217.

Vormbaum, T. (2013). El derecho penal fragmentario en la Historia y la Dogmática (trad. F. Muñoz Conde). Revista Penal 29, 203-222.

Welzel, H. (1970). Derecho Penal alemán. Parte General (trad. de la $11^{a}$ ed. Alemana, J Bustos Ramírez y S. Yáñez Pérez). Santiago de Chile: Editorial Jurídica de Chile.

Wieacker, F. (1957). Historia del Derecho privado en la Edad Moderna (trad. F. Fernández Sardón). Madrid: Aguilar. 